Woolly thinking
$\begin{aligned} & \text { Prion-disease study } \\ & \text { fails to convince over } \\ & \text { risk in sheep } \\ & \text { p760 }\end{aligned}$

\title{
Storm clouds gather over science as war build-up accelerates
}

Matthew Davis, Washington

A long period of expansion for civilian science in the United States looks set to end next year, as President George W. Bush's administration shifts its priorities to wage war against terrorism.

Champions of basic research in Washington seem reconciled to the shift. According to congressional sources, it could easily derail existing plans to double the budget of the National Institutes of Health (NIH) between 1998 and 2003, and require real cuts in basic research funding at the National Science Foundation (NSF), the Department of Energy (DOE) and the space agency NASA.

Mitch Daniels, director of the White House Office of Management and Budget, said in a speech last week that for the 2003 budget, which he is now preparing, initiatives not related to the 11 September terrorist attacks have been deemed "lesser priorities".

The Bush administration was already sceptical about investment in non-biomedical basic research before the attacks (see Nature $413,5 ; 2001)$. In a letter to Nature $(413,566$; 2001), however, Daniels stressed that these programmes would be fairly evaluated according to criteria agreed to by scientists.

But since the attacks, many scientists have become increasingly nervous that their research programmes are about to be branded as luxury items by a government that is interested only in essential goods. Their fears are likely to be confirmed when Bush pub-
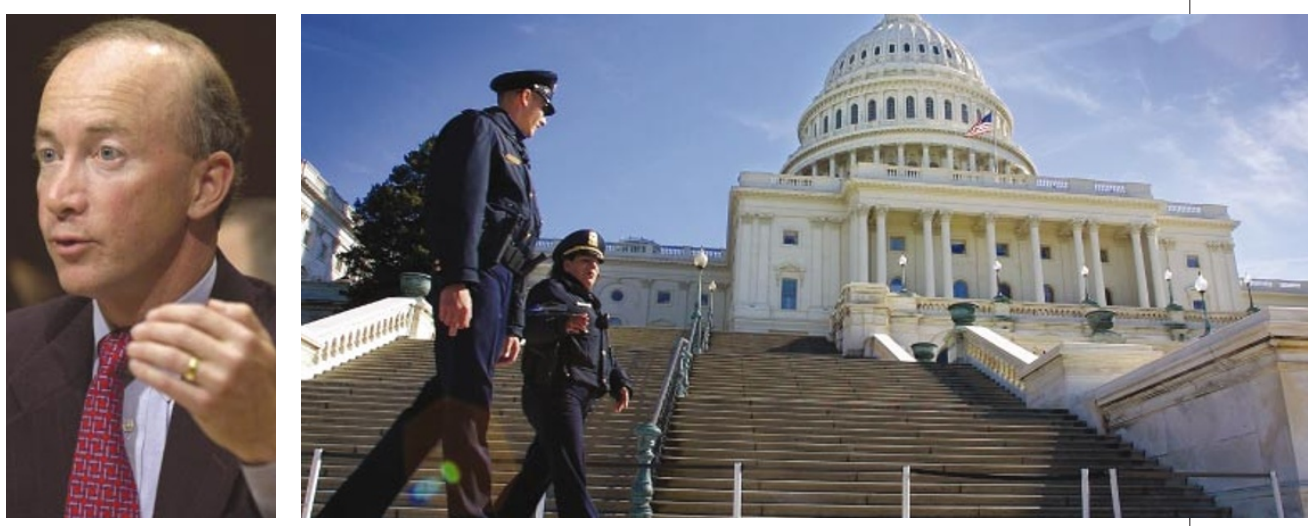

New agenda: as Capitol Hill sat silent last week, Mitch Daniels (left) was revising budget priorities.

lishes his budget proposal for the 2003 fiscal year, next February.

One lobbyist questions whether supporters of biomedical research can, with the exception of work related directly to bioterrorism, "plausibly or honestly make a case that the NIH and basic biomedical research have a role in fighting terrorism". Several lobbyists and congressional staff say the answer is probably "no" and think there is a strong chance that the effort to double the NIH's budget within five years will stop next year, one year short of completion.

Although the NSF is eager to prove its relevance - last week, its website trumpeted the award of a grant to study "human, social responses" to the attacks — a congressional aide who works on its funding predicts that it will be judged harshly — and that members of Congress, including those who strongly support basic research, will accept cuts if they are needed to fund a war.

Political analysts say that Bush will be forced to cut expenditure not relating to war in his 2003 budget to avoid a large deficit. Research and development programmes, which account for about one-seventh of the government's 'discretionary' spending, are obvious targets for such cuts.

So the 2002 budgets set to be completed next week may represent the high watermark for science programmes. The NIH seems likely to receive a \$3-billion increase, and the NSF will be boosted by around $\$ 400$ million, whereas the DOE and NASA will each get about the same as they did this year.

\section{Fallout from terrorism hits summits on developing world}

\section{K. S. Jayaraman, New Delhi,} and Philipp Weis, Munich

The planned Third World Academy of Sciences (TWAS) meeting and a World Food Summit are among the latest events to be postponed in the aftermath of the 11 September attacks on the United States.

The Indian National Science Academy (INSA) was preparing for the eighth TWAS general conference, set to begin in New
Delhi on 27 October, when it was informed of the decision by the TWAS council.

"TWAS decided to postpone the meeting as most of its members and speakers at the meeting were reluctant to undertake a journey to this part of the world in the prevailing situation," says Govardhan Mehta, INSA's president and chairman of the meeting's organizing committee.

Meanwhile, the food summit, organized by the Food and Agriculture Organization and expected to attract more than $\mathbf{1 0 0}$ heads of state, has also been postponed, perhaps until next June.

The summit would have been a follow-up to the first World Food Summit, held in 1996, which declared a goal of halving the number of undernourished people in the world by 2015 . World leaders had been due to meet in Rome on 5-9 November to "outline the measures they envisage for achieving these goals". 